Article

\title{
Research on the Principle of a New Flexible Screw Conveyor and Its Power Consumption
}

\author{
Ye Tian ${ }^{1}{ }^{(1)}$, Panpan Yuan ${ }^{1}$, Fei Yang ${ }^{2, *}$, Jihai Gu ${ }^{1}$, Mengmeng Chen ${ }^{1}$, Junyue Tang ${ }^{2}$, Yilin Su ${ }^{2}$, \\ Tianxiang Ding ${ }^{2}$, Kailiang Zhang ${ }^{2}$ and Qiang Cheng ${ }^{1}$ \\ 1 School of Light Industry, Harbin University of Commerce, Harbin 150028, China; tian8154@126.com (Y.T.); \\ yuanpan1229@163.com (P.Y.); Jihai_gu@163.com (J.G.); m18846137803@163.com (M.C.); \\ cheng9013@126.com (Q.C.) \\ 2 Aerospace Mechanism and Control Center, Harbin Institute of Technology, Harbin 150003, China; \\ tangjunyue922@126.com (J.T.); suyilin1134@126.com (Y.S.); dingtianxiang1122@126.com (T.D.); \\ zhangkailiang2234@126.com (K.Z.) \\ * Correspondence: yangf@hit.edu.cn; Tel.: +86-451-8486-5289
}

Received: 7 April 2018; Accepted: 15 June 2018; Published: 26 June 2018

\begin{abstract}
A new screw conveyor with flexible discrete spiral blades is proposed to solve the problem of particle material gathering between the screw and the tube wall in the traditional screw conveyor. With a theoretical analysis, the power consumption model of the screw conveyor with flexible discrete spiral blades is built. Then, its practicability is verified by simulation and experimental testing. The simulation results show that the increase of the spiral angle will raise the transportation speed of the particles. The diameter of the flexible blades raises with the increase of the power consumption of the screw conveyor. The experimental testing verified the analysis and simulation results.
\end{abstract}

Keywords: screw conveyor; flexible blades; simulation; power consumption; test

\section{Introduction}

Screw conveyors are widely used in modern production and in the logistics of transporting granular materials [1]. When traditional rigid screw conveyors convey sticky bulk materials, the phenomenon of material gathering at the inner wall happens. This will reduce the transmission efficiency of the screw convey.

A flexible tube screw conveyor is proposed in this study to expand the self-loading range. The chief shaft and outer tube are made of rubber, and the screw blade is made of continuous-rigidity plastic. The conveyor to swing widely in a broaden range for the flexibility [2]. A method is proposed to reduce the wear and tear of the screw conveyor. In addition, the power consumption variation of the conveyor transmission affected by the structure parameters of the screw is analyzed [3]. The filling factor of the screw conveyor is a key point for the transmission efficiency. It can be determined by using a ribbon-type screw at different screw speeds [4]. A feeding device based on equal diameter and dual-spiral is designed for animals feeding. The structure parameters and rotary speed are optimized with the simulation software EDEM. Then, the theoretical results are verified by an experimental test [5].

In this paper, a flexible, discrete spiral blades screw conveyor is proposed. The power consumption parameters when using a flexible helical blade structure were studied by theoretical analysis and simulation experiments. 


\section{Analysis of the Mechanical Properties of a Single Flexible Blade}

\subsection{The Radial Analysis of a Single Blade}

Since the fiber length is slightly longer than the inner diameter of the tube wall, the wall of the nylon fiber is shown in Figure 1. A nylon fiber can be idealized as an elongated cylindrical rod. The force passing through the center of the rod cross section, perpendicular to the rod's axis, is the radial force.

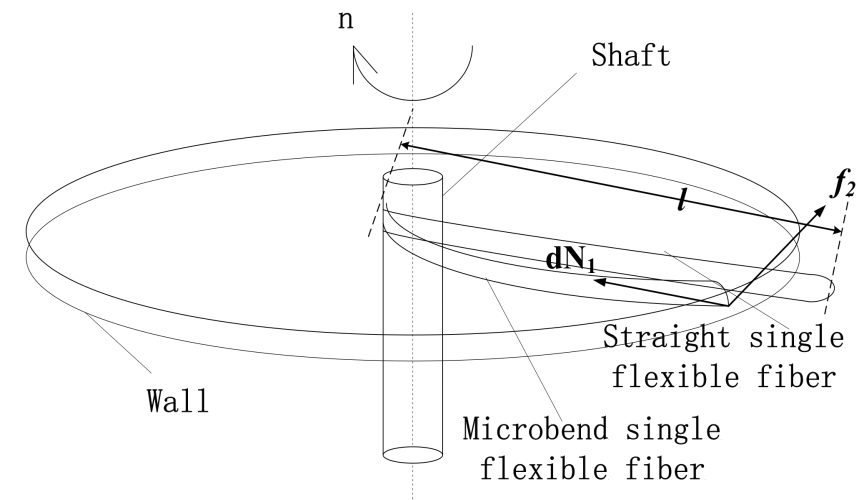

Figure 1. A single flexible blade radial force diagram.

According to Figure 1, the single fiber bundle length is $l, \mathrm{~d} N_{1}$ is a single fiber bend preloaded force, $f_{2}$ is the radial wall of the axial preload force of friction. The fiber bundle is slightly longer than the diameter of the wall.

A single fiber bend force $\mathrm{d} N_{1}$ is:

$$
\mathrm{d} N_{1}=\frac{\pi^{3} E d_{s}^{4}}{256 l^{2}}
$$

where $E$ is the elastic modulus of the material, $d_{s}$ is the diameter of the single nylon fiber, $l$ is the distance between the working point and the supporting point.

\subsection{The Axial Analysis of a Single Blade}

The flexible blades are the elements of the screw conveyor. As a mechanical element, they must possess adequate strength and rigidity. When the end of the nylon fiber axis is fixed on the shaft, the other end is free, so this structure can be considered as a flexible cantilever beam of nylon fibers. The nylon fibers are thin cylinders, and the cross section of each fiber is circular. The force analysis is shown in the Figure 2.

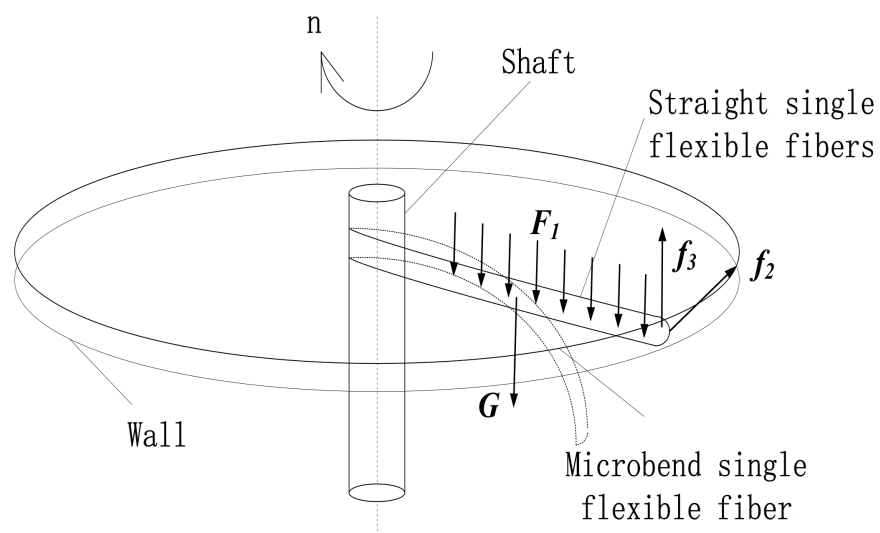

Figure 2. Single flexible helical blade axial force diagram. 
In the Figure 2, $F_{1}$ is caused by the weight of the material of the uniformly distributed load. Since there is no granule material, the study of the screw conveyor is an idealization. $f_{3}$ is the radial wall friction preload in the axial direction.

When the fiber bundle gets bent, resistance to bending internal forces will be produced as well. Depending on the shape of the material, the internal forces resisting deformation are different. The formula of the maximum bending stress of the fiber bundles is:

$$
\sigma_{\max }=\frac{\mu_{1} \mathrm{~d} N_{1} l}{0.2 d_{s}^{3}}
$$

The friction along the axial preload is $f_{3}$, so its maximum deflection $W_{\max }$ is:

$$
W_{\max }=\frac{64 f_{3} l^{3}}{3 \pi E d_{s}^{4}}
$$

\subsection{The Structural Parameters Analysis of the Flexible Blade}

The material of the flexible blade is wear-resistant fiber. The flexible screw diameter is slightly longer than the spiral pipe's diameter. According to the principle of material mechanics [6-8], the flexible blade is bent and contacts the inner wall of the tube. With the fibers rotation, there is no material-gathering phenomenon occurring. The structural parameters of the flexible blade are shown in Figure 3.

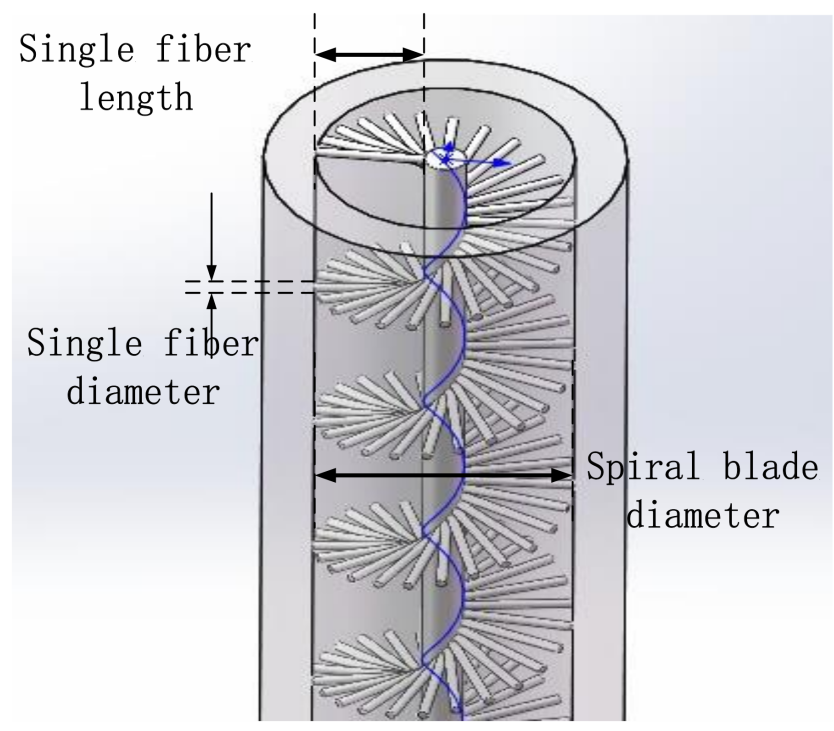

Figure 3. Flexible blade characteristics.

Based on Formula (1):

$$
l=\frac{\pi d_{s}^{2}}{4} \sqrt{\frac{E \pi}{d N_{1}}}
$$

$d_{\mathrm{s}}$ is from $0.5 \mathrm{~mm}$ to $2.5 \mathrm{~mm} . E$ is $3.2 \times 10^{9} \mathrm{~N} / \mathrm{m}^{2} . d N_{1}=100 \mathrm{~N}, 1.5625 \mathrm{~mm} \leq l \leq 39 \mathrm{~mm}$, Stress must satisfy the condition that, less than the allowable stress $[\sigma]$, the material or institutions allowable stress is the national standard.

$$
\sigma_{\max } \leq[\sigma]
$$


Based on Formula (2), $l$ is:

$$
l \leq \frac{0.2 d_{s}^{3}[\sigma]}{\mu_{1} \mathrm{~d} N_{1}}
$$

$[\sigma]$ of nylon 66 is $12 \mathrm{MPa}, d N_{1}=100 \mathrm{~N}$, the friction factor between plastic and plastic $\mu_{k}$ is 0.4 , the calculation is

$$
1.5 \mathrm{~mm} \leq l \leq 187.5 \mathrm{~mm}
$$

The design should meet the stiffness conditions as follow:

$$
\omega_{\max }=\frac{64 f_{3} l^{3}}{3 \pi E d_{s}^{4}} \leq[\omega]
$$

The formula is:

$$
l \leq \frac{1}{8} \sqrt[3]{\frac{3 \pi E d_{s}^{4}[\omega]}{f_{3}}}
$$

With $d_{\mathrm{s}}$ from $0.5 \mathrm{~mm}$ to $2.5 \mathrm{~mm}$, and $f_{3}=30 \mathrm{~N}$, the calculation is:

$$
6.5 \mathrm{~mm} \leq l \leq 38.75 \mathrm{~mm}
$$

\subsection{The Flexible Blade Discrete Coefficient}

As can be seen from Figure 4, the flexible spiral blade adopts a spiral form similar to that of the traditional spiral blade. This structure can make the material rising along the surface. When the gap between two fibers is too big, the flexible blade cannot meet the requirements of the conveying material blade. If the gap is small, the power consumption will be increased.

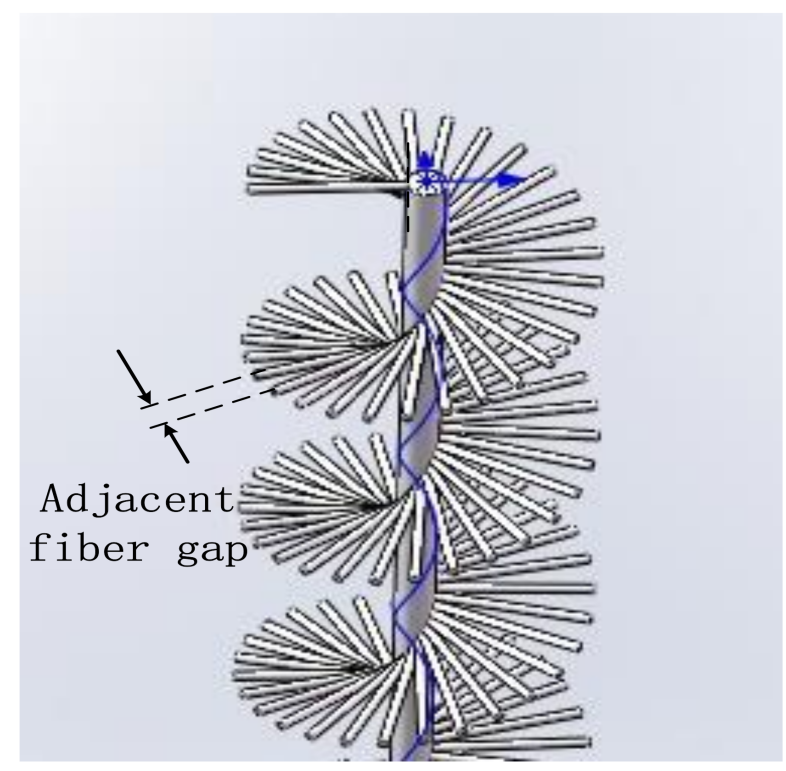

Figure 4. Flexible helix blade clearance diagram.

The discrete coefficient $\lambda$ formula is:

$$
\lambda=\frac{d_{j}}{d_{i}+d_{j}}
$$

where $d_{i}$ is the diameter of the nylon, and $d_{j}$ is the average distance between two nylon fibers. 


\section{The Conveying Power Consumption Model}

\subsection{Single Particle Motion Analysis}

We assume that the granular material is a continuous medium [9-12], and the particle size, shape and natures are the same. The material on the spiral vane motion analysis is shown in Figure 5.

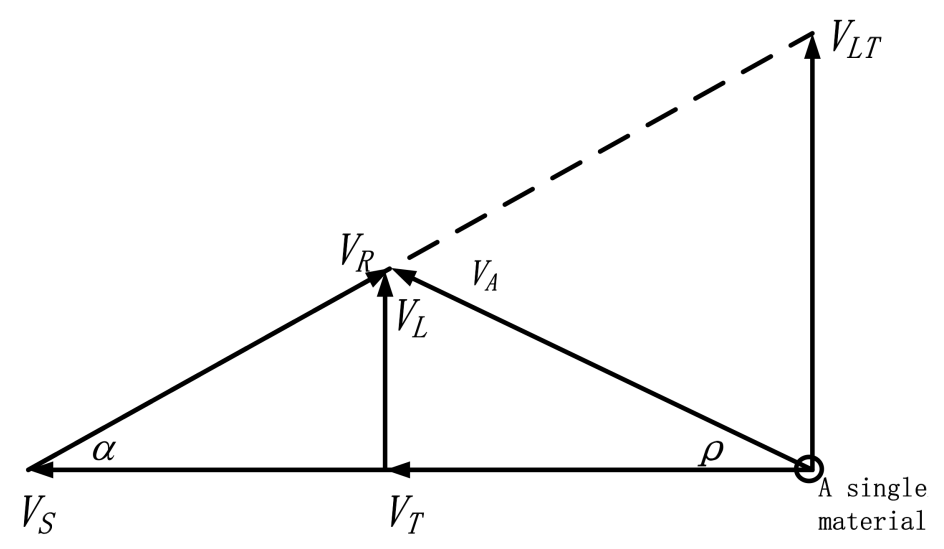

Figure 5. Diagram of the velocity of a single particle.

In Figure 5, $V_{S}$ is the screw rotational speed, $V_{R}$ is the relative speed of material along the spiral surface, $V_{A}$ is the speed of the material, $V_{L T}$ is the speed of the screw conveyor, $V_{\mathrm{T}}$ is the transport velocity.

The spiral angle of the blade is:

$$
\alpha=\tan ^{-1} \frac{P}{\pi D}
$$

The tangential velocity $V_{S}$ of the material is:

$$
V_{S}=\omega R=\frac{2 \pi n R}{60}=\frac{\pi n_{z} R}{30}
$$

where $R$ is the radius from the centerline of the screw axis to the wall, and $n_{\mathrm{z}}$ is the screw shaft speed. Therefore, the tangential velocity of the material increases with the acceleration of the rotation speed of the helical shaft and the increase of the helical radius. The relative speed of the material along the spiral surface $V_{R}$ is:

$$
V_{R}=\frac{V_{S} \sin \rho}{\sin (\alpha+\rho)}
$$

The synthesis speed $V_{A}$ is:

$$
V_{A}=\frac{V_{S} \sin \alpha}{\sin (\alpha+\rho)}
$$

Figure 5 shows the vertical speed of the materials that is:

$$
V_{L}=\frac{\pi n_{z} R \sin \alpha \sin \rho}{30 \sin (\alpha+\rho)}
$$

\subsection{Power Consumption Calculation}

The friction consumption of fibers is $P_{1}$

As shown in the Figure 6, the frictional force can be represented as:

$$
d f_{1}=\tan \delta \rho_{(z)} h b g \mathrm{~d} l \cos \alpha
$$


where $\rho_{(z)}$ is the density of the powder material, $h$ is the thread height, $b$ is the spiral groove width, $\mathrm{d} l$ is the length along the spiral element, and $\delta$ is the friction angle.

The corresponding torque infinitesimal $\mathrm{d} M_{1}$ can be represented as:

$$
\mathrm{d} M_{1}=\frac{1}{2}\left(D-d_{Z}\right) \rho_{(z)} h b g \tan \delta \cos \alpha \lambda \frac{\pi D}{p} \mathrm{~d} z
$$

where $D$ is the diameter of the inner wall, and $d_{z}$ is the screw shaft outer diameter.

By the formula $P=M \omega$, we have:

$$
P_{1}=M_{1} \omega=\omega \int_{0}^{z} \frac{\left(D-d_{Z}\right) \rho_{(z)} h b g \tan \delta \cos \alpha \lambda \pi D}{2 p} \mathrm{~d} z
$$

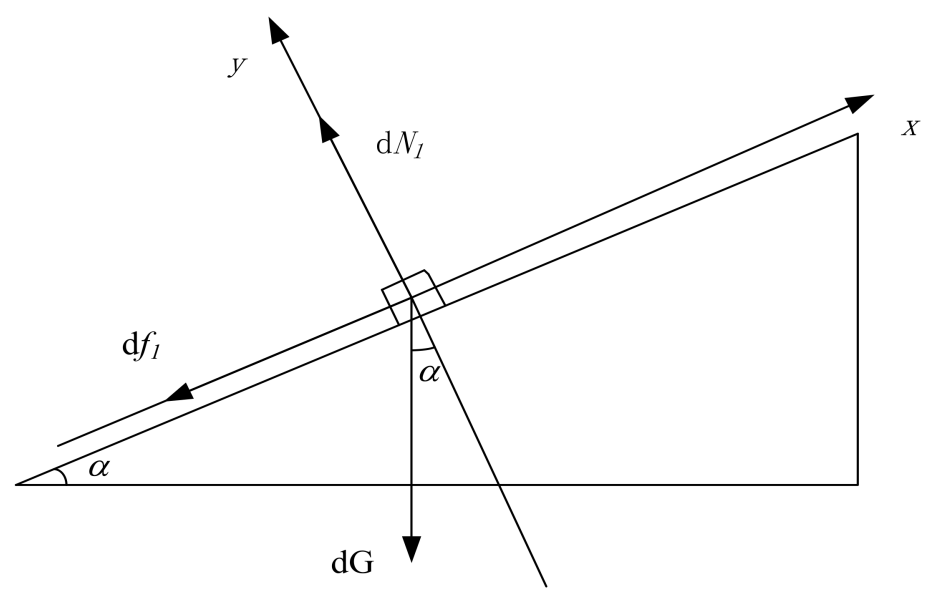

Figure 6. Diagram of the stress of the material along the spiral surface.

In Figure 7, the frictional force $d f_{2}$ is:

$$
d f_{2}=\tan \delta_{1} \omega^{2} \frac{D-d_{Z}}{2} d m=\frac{\rho_{(z)} h b \omega^{2}\left(D-d_{Z}\right) \pi D \tan \delta_{1}}{2 p} \mathrm{~d} z
$$

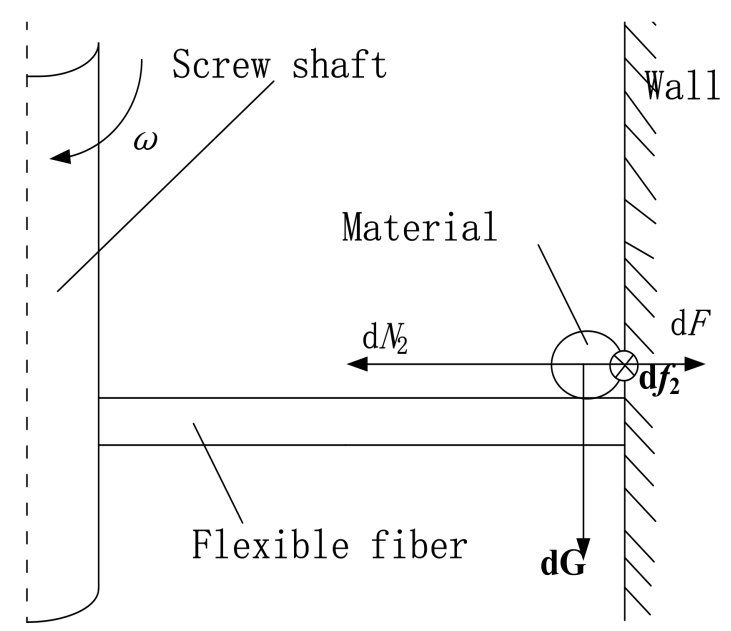

Figure 7. Vertical plane stress analysis. 
The corresponding torque infinitesimal $\mathrm{d} M_{2}$ can be represented as:

$$
\mathrm{d} M_{2}=\frac{D-d_{Z}}{2} d f_{2}=\frac{\left(D-d_{Z}\right)^{2}}{4} \frac{\rho_{(z)} h b \omega^{2} \pi D \tan \delta_{1}}{p} \mathrm{~d} z
$$

The consumption of the material due to the interaction with the spiral wall is $P_{2}$.

By the formula $P=M \omega$, we have:

$$
P_{2}=M_{2} \omega=\frac{\omega\left(D-d_{Z}\right)^{2} h b \omega^{2} \pi D \tan \delta_{1}}{4 p} \int_{0}^{z} \rho_{(z)} \mathrm{d} z
$$

Power is required to overcome the elastic deformation of the flexible helical fibers $[13,14]$. When the flexible screw rotates with the helical axis, the centrifugal force of single fiber will produce a force $f_{0}$ on tangent direction.

$f_{4}$ is the difference between $\mathrm{d} N_{1}$ and $f_{0}$. It is the elastic potential energy, as shown in Figure 8.

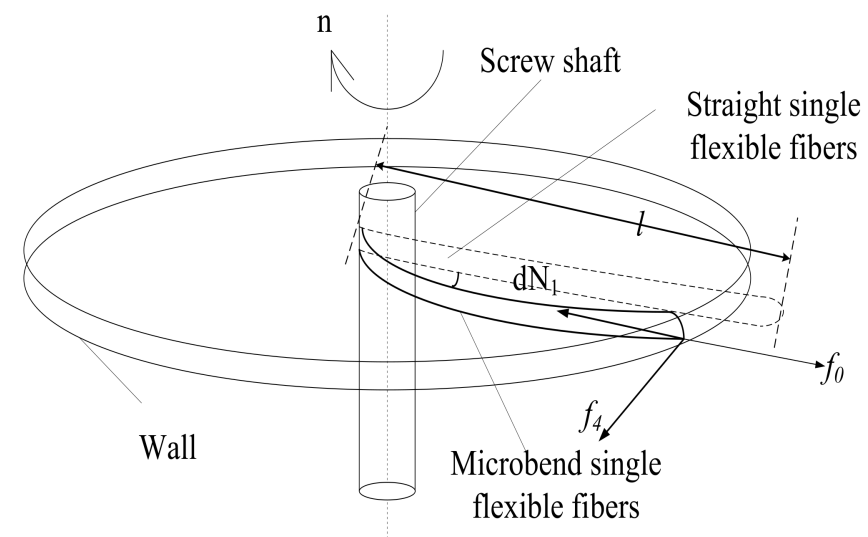

Figure 8. Stress analysis of the elastic deformation of the flexible spiral strand.

The centrifugal force $f_{0}$ and the friction force $f_{4}$ are:

$$
\begin{gathered}
f_{0}=m \omega l^{2} \\
f_{4}=\mu m \omega l^{2}+f_{3}
\end{gathered}
$$

where $m$ is the quality of a single fiber, and $\omega$ is the rotating speed of the screw shaft.

We assumed the elastic potential energy of the fibers as the elastic potential energy of a spring:

$$
E_{P}=\frac{1}{2} k \delta^{2}
$$

where $\delta$ is the deformation of the fiber bundle, and $k$ is the spring stiffness which depends on the material itself:

$$
\delta=\frac{f_{4} l}{\mathrm{E} A}
$$

The total elastic energy of the nylon fiber is:

$$
E_{z}=N E_{p}=\frac{1}{2} \mathrm{~N} k\left[\frac{\left(\mu m \omega l^{2}+\mu d N_{1}\right) l}{\mathrm{E} \pi d_{s}^{2}}\right]^{2}
$$


We can obtain the total power consumption of elastic energy of the nylon fiber:

$$
P_{3}=\frac{E_{Z}}{t}=\frac{1}{2 t} \mathrm{~N} k\left[\frac{\left(\mu m \omega l^{2}+\mu d N_{1}\right) l}{\mathrm{E} \pi d_{s}^{2}}\right]^{2}
$$

where $t$ is the working time.

To sum up, the total power consumption $P$ is:

$$
\left\{\begin{array}{c}
P_{1}=M_{1} \omega=\omega \int_{0}^{z} \frac{\left(D-d_{Z}\right) \rho_{(z)} h b g \tan \delta \cos \alpha \lambda \pi D}{2 p} \mathrm{~d} z \\
P_{2}=M_{2} \omega=\frac{\omega\left(D-d_{Z}\right)^{2} h b \omega^{2} \pi D \tan \delta_{1}}{4 p} \int_{0}^{z} \rho_{(z)} \mathrm{d} z \\
P_{3}=\frac{E_{Z}}{t}=\frac{1}{2 t} \mathrm{~N} k\left[\frac{\left(\mu m \omega l^{2}+\mu d N_{1}\right) l}{\mathrm{E} \pi d_{s}^{2}}\right]^{2} \\
P=P_{1}+P_{2}+P_{3}
\end{array}\right.
$$

\section{Discrete Element Simulation}

The Discrete Element Method (EDEM) software is used to simulate the process of a flexible screw conveyor transporting granular materials [15-18]. In the software, the flexible screw, tube wall,

\begin{tabular}{|c|c|c|c|}
\hline Material & Poisson's Ratio & Modulus of Elasticity (pa) & Density $\left(\mathrm{kg} / \mathrm{m}^{3}\right)$ \\
\hline Starch & 0.25 & $2 \times 10^{7}$ & 1500 \\
\hline Nylon 66 & 0.28 & $3.2 \times 10^{9}$ & 1130 \\
\hline PVC & 0.35 & $3 \times 10^{6}$ & 1400 \\
\hline
\end{tabular}
and granular material are built [19]. The material's parameters [20-23] are shown in Table 1.

Table 1. Material properties.

The starch granules contact properties are shown in the Table 2, and the contact models in simulation are shown in Table 3.

Table 2. Starch granules' contact properties.

\begin{tabular}{cccc}
\hline Interaction & Coefficient of Restitution & Static Friction Coefficient & Rolling Friction Coefficient \\
\hline Particle to particle & 0.1 & 0.7 & 0.01 \\
Particles to nylon & 0.3 & 0.5 & 0.01 \\
$\begin{array}{c}\text { Particles to PVC } \\
\text { tube }\end{array}$ & 0.3 & 0.5 & 0.01 \\
\hline
\end{tabular}

Table 3. Physical interaction model.

\begin{tabular}{cc}
\hline Interaction & Model \\
\hline Particle to particle & Mertz-Mindin with bonding built-in \\
Particles to nylon & Mertz-Mindin (no slip) built-in \\
Particles to PVC tube & Mertz-Mindin (no slip) built-in \\
\hline
\end{tabular}

\subsection{The Spiral Angle}

Considering the limits of the manufacturing capacity, the spiral angles of the flexible screw conveyor is $20^{\circ}$, and the diameter of the spiral is $70 \mathrm{~mm}$, which is the capability of the screw. Therefore, the maximum distance of each fiber is $1 \mathrm{~mm}$, and the diameter of the spiral is $70 \mathrm{~mm}$. The spiral shaft is $150 \mathrm{~mm}$ long, and the rotational speed is $400 \mathrm{rpm}$. The particle number is 10,000. We set three spiral angles of $10^{\circ}, 20^{\circ}$, and $30^{\circ}$ to simulate the process of the flexible screw working. Figure 9 shows the simulation results. 
The low-speed material particles are colored in blue, and the high-speed particles are colored in red. It can be seen from Figure 9a that for most of the particles, the speed is from $100 \mathrm{~mm} / \mathrm{s}$ to $480 \mathrm{~mm} / \mathrm{s}$. In Figure 9b, the speed of most particles is from $400 \mathrm{~mm} / \mathrm{s}$ to $860 \mathrm{~mm} / \mathrm{s}$. In Figure 9c, the speed of most particles speed is from $800 \mathrm{~mm} / \mathrm{s}$ to $1200 \mathrm{~mm} / \mathrm{s}$. The results show that the speed of the particles can be increased by the speed of the screw conveyer under certain other conditions. By collating the simulation data, the speed of the three experiments at the same transportation distance is shown in Figure 10.

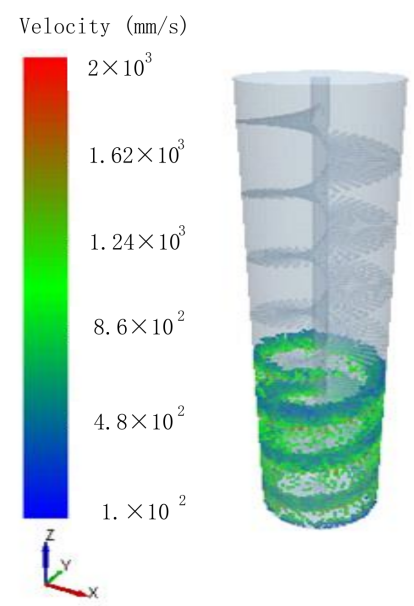

(a)

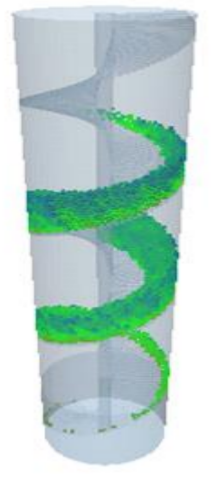

(b)

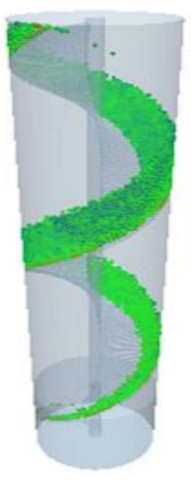

(c)

Figure 9. Different angles simulation results. (a) spiral angle $10^{\circ}$; (b) spiral angle $20^{\circ}$; (c) spiral angle $30^{\circ}$.

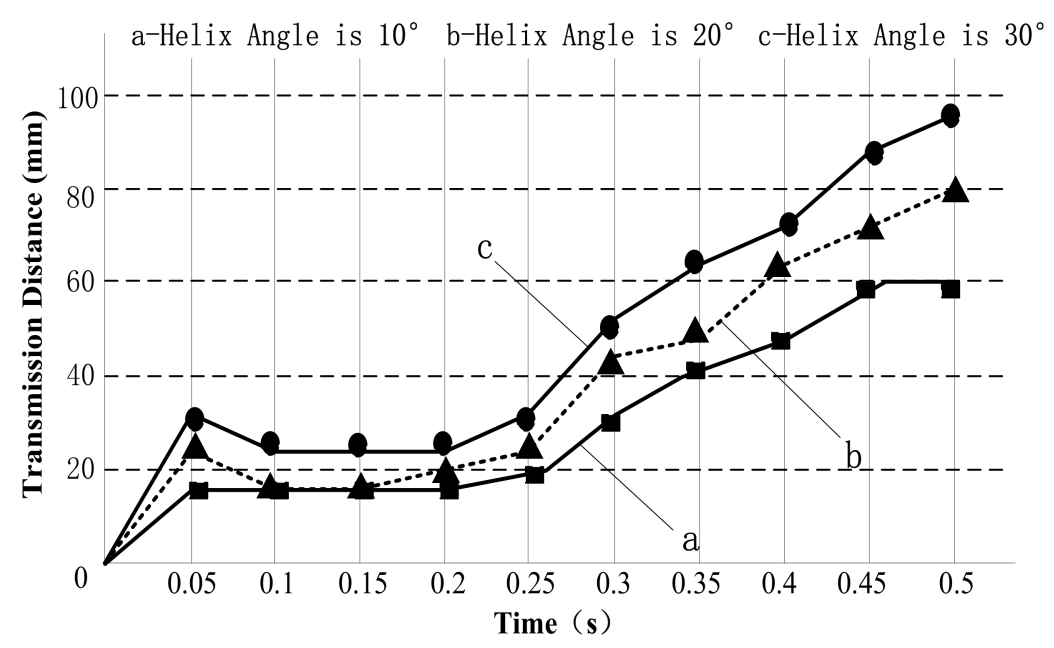

Figure 10. Transmission distance with different angles.

From Figure 10, it can be seen that increases of the spiral angle will improve the transportation efficiency of the granular material.

\subsection{The Different Rotary Speed}

The rotary speeds of the motor are $200 \mathrm{rpm}, 600 \mathrm{rpm}$, and $800 \mathrm{rpm}$. We can see from Figure 11a that the rotary speeds of most particles are from $100 \mathrm{rpm}$ to $2000 \mathrm{rpm}$. The particles rotate with the rotation of the helical axis, but the upward transport of the particles is not obvious. We can see from Figure $11 \mathrm{~b}$ that the speed of most particles is between $100 \mathrm{rpm}$ to $5000 \mathrm{rpm}$. The particles rotate with 
the rotation of the helical axis, and the upward transport of the particles is obvious. The speed of the particles are from $1000 \mathrm{rpm}$ to $8000 \mathrm{rpm}$ in Figure 11c.

The data collected are shown in Figure 12. This shows that, under certain conditions, the transport of the particles increases with the increase of the speed of the screw conveyor.

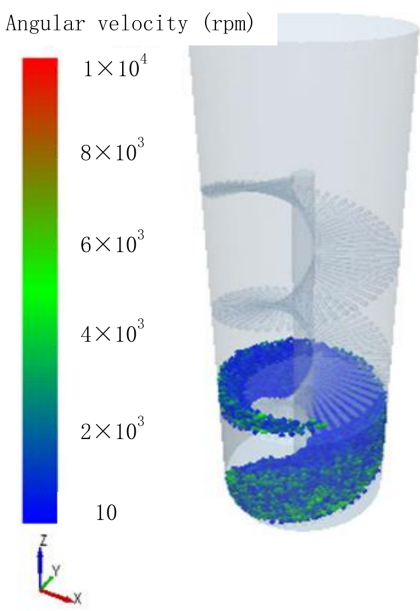

(a)

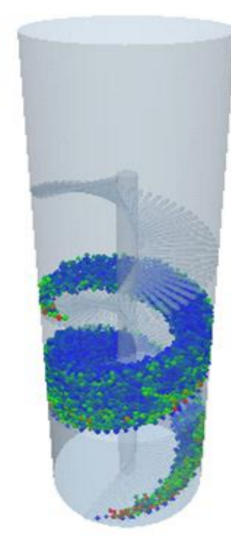

(b)

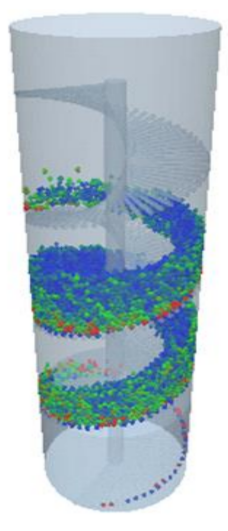

(c)

Figure 11. Different rotary speeds simulation. (a) Rotary speed 200 rpm; (b) rotary speed 600 rpm; (c) rotary speed $800 \mathrm{rpm}$.

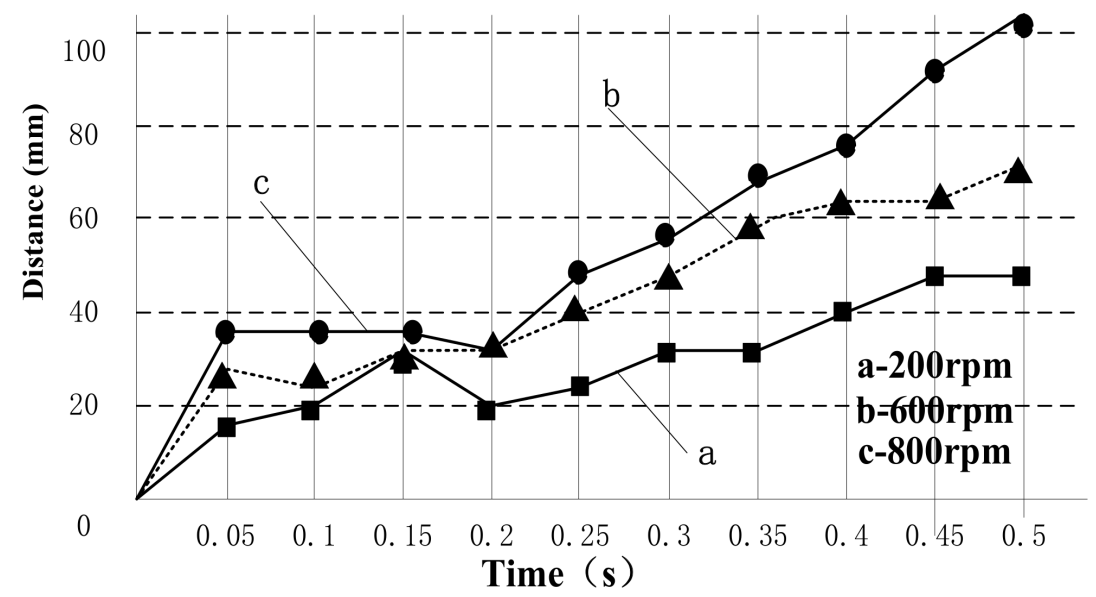

Figure 12. Particles speed with different rotary speeds.

\section{Test and Results}

\subsection{Experiments}

The experiments performed regard the sensor, rotary motor, tube and screw, data collection device, as can be seen from Figure 13a,b. The rotary speed range is from $100 \mathrm{rpm}$ to $1000 \mathrm{rpm}$. Figure 14 shows the flexible blade screw conveyor, which is composed of tube, flexible blade, and axis. The conveyor is $2 \mathrm{~m}$ long, the diameter is $60 \mathrm{~mm}$, and the screw angle is $20^{\circ}$. The transportation object is sand with homogeneous particle size. 


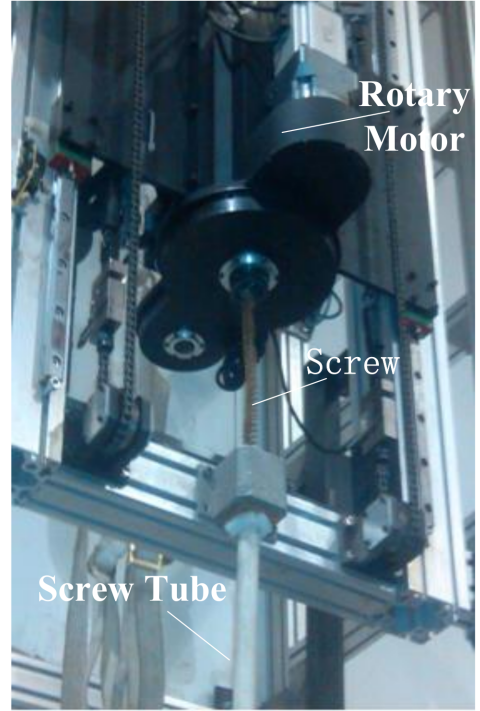

(a)

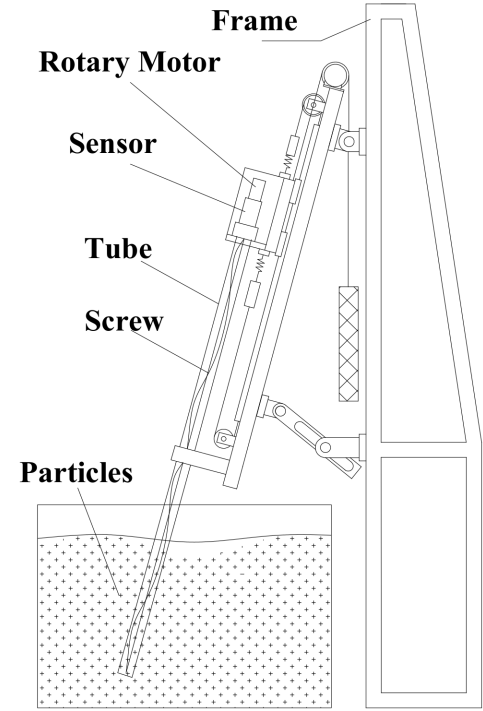

(b)

Figure 13. Test bed and parts. (a) Test bed. (b) Parts of test bed.

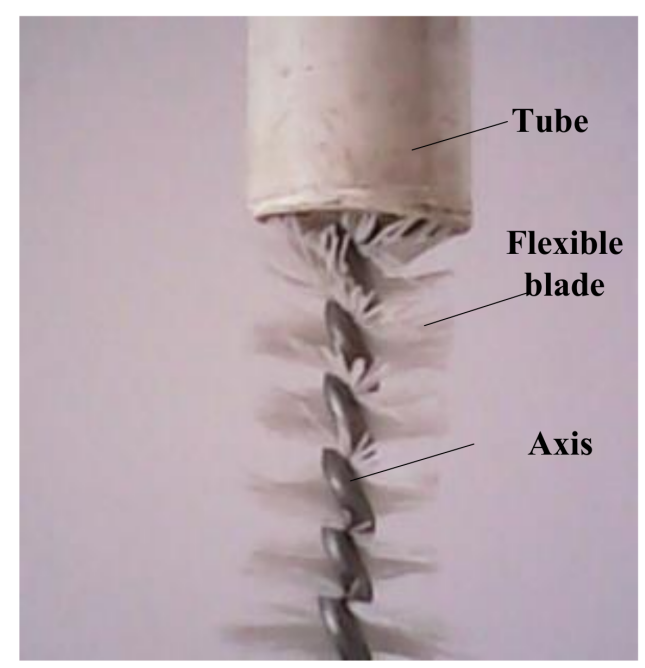

Figure 14. Flexible blade screw.

\subsection{Results}

In order to eliminate the adverse effects of No-load of the rotary motor, rotary torque curves without load were obtained from $100 \mathrm{rpm}$ to $300 \mathrm{rpm}$. Figure 15 is a torque curve without load under $300 \mathrm{rpm}$. The other two torque curves are the same as in Figure 15. As we can see, the curve are similar to a horizontal straight line, and the value is $0.40 \times 10^{4} \mathrm{Nm}$.

As shown in the Figure 16, the three curves indicate the torque consumption under load. The data obtained with the Matlab software, are shown in Figure 17. The three lines represent test data, simulation data, and numerical solution when the rotary speed is $300 \mathrm{rpm}$. The numerical solution by the model is a limited data. Therefore, it is a horizontal line in Figure 17. In contrast, the test and simulation curves are obtained at the same time. It can be seen that the two curves raise with time, but the maximum values are lower than the numerical solution. 


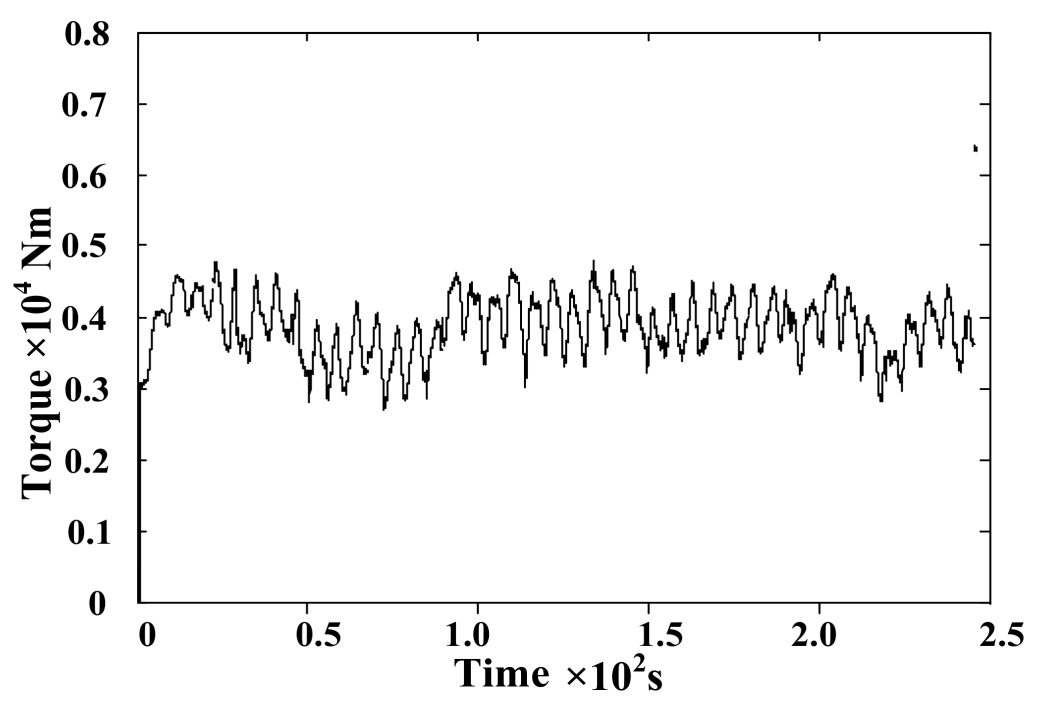

Figure 15. Torque without load.

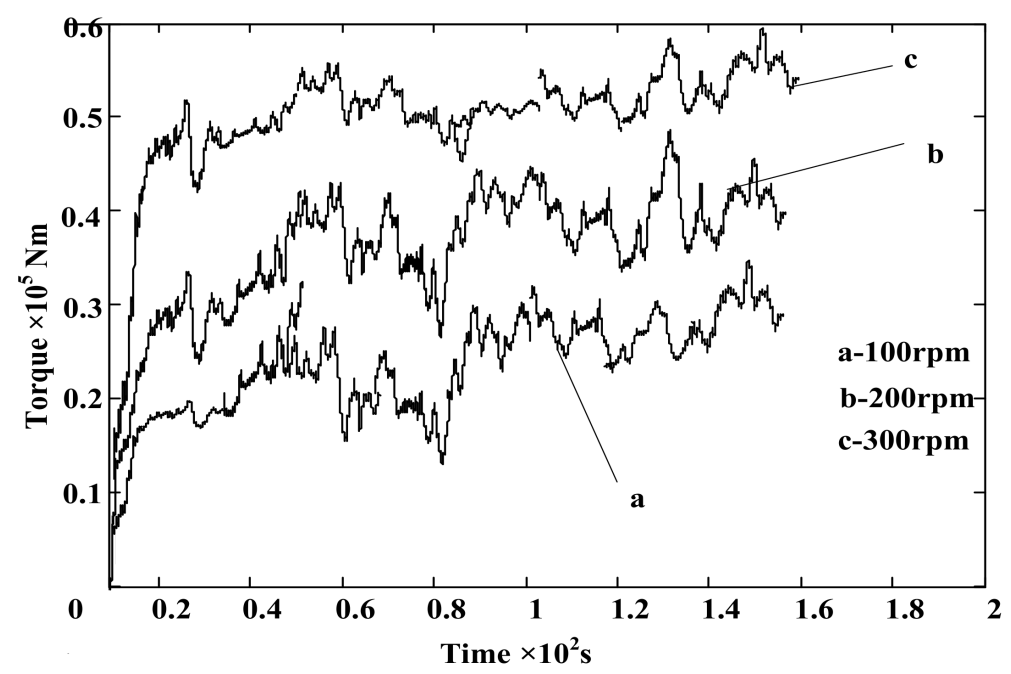

Figure 16. Torque of three rotary speeds.

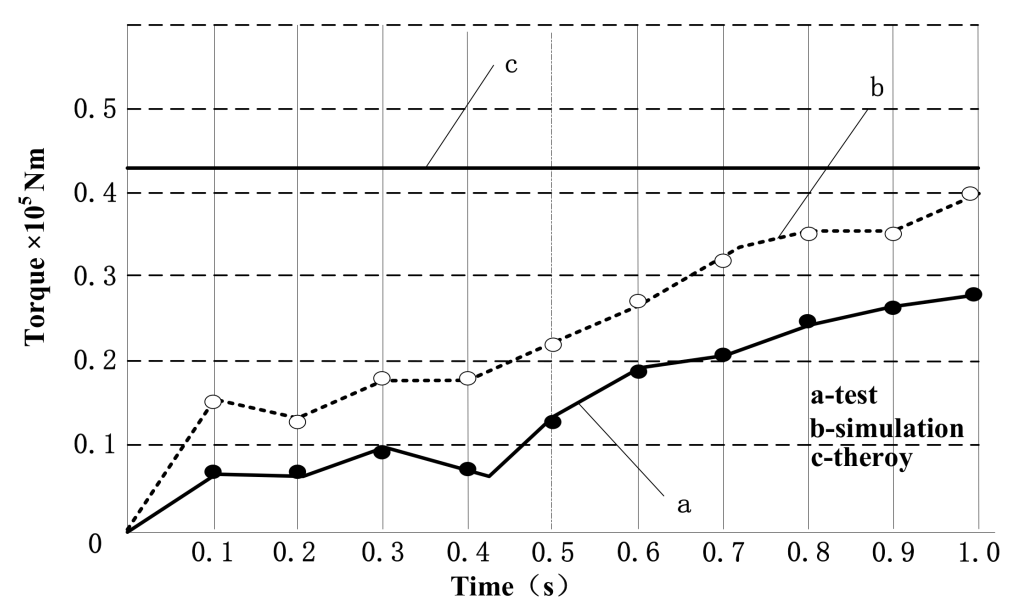

Figure 17. Contrast diagram. 


\section{Conclusions}

The conclusions of this paper can be summarized as follows:

(1) A flexible screw blade which is made of flexible fiber bundles is proposed as the spiral conveying shaft of screw conveyor for powder conveying. The ability to transmit particles whose diameter is bigger than that of the flexible fibers is verified by experiments.

(2) According to the theory of particle mechanics and material mechanics, the power consumption and conveying quantity model of flexible screw blades for conveying bulk materials are established. The main parameters affecting the conveying amount and power consumption are: helical diameter, spiral rising angle, blade dispersion coefficient, and so on.

(3) The mechanism of flexible spiral blade conveyor is verified by the particle material mechanics software EDEM. From the results of the simulation, we show that the conveying capacity of the particles decreases with the acceleration of the clearance of the flexible helical blades and increases with the speed, diameter, and angle of the screw conveyer; the power consumption of the particle material increases with the speed of the screw conveyor and the diameter of the spiral.

(4) The theoretical and simulation results are verified by experiments. By comparing the power (torque) curves at the same speed, the growth trend of the experimental curves is consistent with the results of the theoretical analysis and simulation curves.

Author Contributions: Y.T. and J.G.; Methodology, M.C.; Software, P.Y.; experiment, Y.S. and T.D.; Data Analysis, F.Y. and J.T.; Validation, K.Z.; Writing-Original Draft Preparation, Q.C.; Editing paper format.

Acknowledgments: This research was supported by the National Natural Science Fund (41772387), Youth Innovative Talent Support Project of Harbin University of Commerce (2016QN067), doctoral research startup project (2016BS07).

Conflicts of Interest: The authors declare no conflict of interest.

\section{References}

1. Wang, D.-X. Research on Numerical Analysis and Optimal Design of the Screw Conveyor. Univ. Technol. 2012, 27, 32-36.

2. Hevko, R.B.; Rozum, R.I.; Klendii, O.M. Development of Design and Investigation of Operation Processes of Loading Pipes of Screw Conveyors. Agric. Eng. 2016, 3, 200-210.

3. Hu, K. Screw conveyor principle and design. J. Nanchang Univ. (Engl. Ed.) 2000, 4, 30-36.

4. Mondal, D. Study on filling factor of short length screw conveyor with flood-feeding condition. Mater. Today Proc. 2018, 5, 1286-1291. [CrossRef]

5. Qi, J.; Meng, H.; Kan, Z.; Li, C.; Li, Y. Analysis and test of feeding performance of dual-spiral cow feeding device based on EDEM. Trans. Chin. Soc. Agric. Eng. 2017, 33, 65-71.

6. Zhao, W.-M.; Li, G.-X. Screw Drill Test for Soil Delivering Speed and Resistance. Constr. Mach. 2006, 37, 23-25.

7. David, R. Gill Basics of Flexible Screw Conveyors. Plant Eng. 2003, 25, 232-235.

8. Spiroflow Clitheroe Lances. Flexible Screw solves sticky problem. Prof. Eng. 2002, 45, 118-121.

9. Xu, D.-W.; Liu, G.-B.; Cheng, D.-W. Design and Construction of the TPS310 Screw Conveyor. Packag. Food Mach. 2002, 20, 35-37.

10. Liu, Z.-K.; Liu, Y.-Z. Analysis and Calculation of Powder of Screw Conveyor. Feed Ind. 1987, 5, 32-36.

11. Huang, S.-Y. Mechanics of Granular; Machinery Industry Press: Beijing, China, 1993; pp. 42-45.

12. Kapur, P.C.; Meloy, T.P. Industrial Modeling of Spirals for Optimal Configuration and Design: Spiral Geometry, Fluid Flow and Forces on Particles. Powder Technol. 1999, 102, 244-252. [CrossRef]

13. Woodcock, C.R.; Mason, J.S. Bulk Soilds Handling; Black \& Son Limited: London, UK, 1987.

14. Uchida, K.; Okamoto, K. Measurement Technique on the Diffusion Coefficient of Powder Flow in a Screw Feeder by X-ray Visualization. Powder Technol. 2008, 187, 138-145. [CrossRef]

15. Lv, B.-Y. Manufacturing and forming technology of the blade of a screw conveyer. For. Mach. Woodwork. Equip. 2009, 37, 49-51. 
16. Roberts, A.W. Design and Performance Criteria for Screw Conveyors in Bulk Solides Operation. Bulk Solids Handl. 2002, 22, 436-444.

17. Morton, W.E.; Hearle, J.W.S. Physieal Properties of Textile Fibres, 2nd ed.; William Heinemann Ltd.: London, UK, 1975; pp. 399-440.

18. Xu, Y.; Sun, Q.-C.; Zhang, L. Research Progress on Particle Discrete Element Method. Adv. Mech. 2003, 33, 251-256.

19. Sun, L.-M. Research on the Current Situation and Development of Mechanics of Granular. J. Kaifeng Univ. 2011, 25, 74-77.

20. Zhu, L.-T. The Mechanical Properties of the Fiber Strain Rate Effect and Knitted Composite Ballistic Impact Damage Mechanism. Donghua Univ. 2010, 6, 32-36.

21. Yan, Z.-J. Study on structural change of fiber and its composites mechanical properties and fracture process. Synth. Fiber 2010, 28, 46-48.

22. Li, J.-H.; Fu, C.-M.; Xia, P. Optimization Design of Screw Conveyor Mode Based on Simulation. Mech. Sci. Technol. 2011, 30, 512-516.

23. Tian, Y.; Deng, Z.-Q.; Tang, D.-W. Structure Parameters Optimization and Simulation Experiment of Auger in Lunar Soil Drill-sampling Device. Chin. J. Mech. Eng. 2012, 48, 10. [CrossRef]

(C) 2018 by the authors. Licensee MDPI, Basel, Switzerland. This article is an open access article distributed under the terms and conditions of the Creative Commons Attribution (CC BY) license (http:/ / creativecommons.org/licenses/by/4.0/). 